\title{
PENTINGNYA PENGINDEKSAN KOLEKSI DALAM PROSES TEMU BALIK INFORMASI DI PERPUSTAKAAN
}

\author{
Jati Rahadi \\ Fridinanti Yusufhin \\ UIN Sulthan Thaha Saifuddin Jambi \\ Email:jatigunners@gmail.com
}

\begin{abstract}
ABSTRAK
Artikel ini membahas pentingnya pengindeksan dalam proses temu kembalinya informasi di perpustakaan. Tujuan pengindeksan adalah membantu menemukan informasi secara tepat dan cepat. Tidak hanya itu, peran pengindeksan dituntut harus cepat dan tepat dalam menentukan keyword. Pada hakikatnya pengindeksan sangat penting untuk pencarian informasi. Karena di era millenial saat ini, masyarakat didukung oleh bantuan teknologi yang semakin menuntut akses informasi yang cepat dan akurat. Pengindeksan koleksi merupakan salah satu aspek penting dalam proses information retrieval. Pada prosesnya dituntut jangan sampai salah membuat informasi mengenai isi buku atau dokumen tersebut. Sehingga tujuan yang diharapkan oleh perpustakaan tercapai sesuai apa yang telah direncanakan.
\end{abstract}

Kata Kunci: Pengindeksan, Temu Balik Informasi, Perpustakaan

\section{PENDAHULUAN}

Perpustakaan merupakan salah satu tempat dikumpulkannya berbagai sumber informasi. Didalamnya terdapat beragam informasi, mulai dari informasi lokal sampai lingkup internasional. Informasi-informasi tersebut dimuat didalam sebuah bentuk yang populer disebut dengan koleksi. Koleksi diperpustakaan sangat bermanfaat bagi masyarakat penggunanya baik itu di sekolah, perguruan tinggi, maupun instansi lainnya yang dapat diakses oleh semua kalangan masyarakat.Koleksi yang berada didalam perpustakaan tersebut tentu harus dapat diakses dengan mudah oleh penggunanya.

Menurut Rudianto (2017:2),salah satu hal yang sangat penting bagi sebuah perpustakaan adalah koleksi. Namun disamping itu, adapun yang lebih penting lagi, yaitu bagaimana cara kita memperoleh koleksi itu dengan cepat, tepat dan akurat tanpa harus membuang banyak waktu dan sesuai dengan keinginan pengguna.Dalam hal ini, untuk mewujudkan akses koleksi di perpustakaan yang mudah,cepat dan akurat ada beberapa proses yang harus dikerjakan, yaitu melakukan proses penyusunan katalog di perpustakaan dan penyusunan indeks subjek pada sebuah buku. Kagiatan ini disebut pengindeksan.

Menurut Basuki (2004:163), indeks adalah nama, subjek, kata kunci atau topik lain yang disusun menurut urutan tertentu untuk memudahkan proses temu balik dokumen/informasi. Dengan demikian seorang pembaca yang ingin 
menemukan sebuah istilah dalam sebuah dokumen harus berusaha mencari pada indeks yang terdapat pada bagian belakang dokumen.Menurut Suhendar (2010:1), katalog merupakan daftar bahan pustaka baik berupa buku maupun non-buku seperti majalah, surat kabar, mikrofilm, slide dan sebagainya yang mencantumkan informasi-informasi penting dari suatu bahan pustaka baik menyangkut fisik,isi seperti edisi, cetakan, tahun terbit, penerbit, ISBN, dan lain-lain.

Katalog perpustakaan sangat penting untuk temu balik informasi bagi pemustaka, keberadaanya diperlukan untuk menjembatani pengguna dengan koleksi yang berisi informasi yang dibutuhkan pengguna. Oleh karena itu, pembuatan katalog koleksi di perpustakaan harus tepat dan akurat sesuai dengan koleksinya sehingga temu balik informasi tidak terganggu. Dalam pembuatan katalog perpustakaan, analisis subjek juga penting disamping notasi atau nomor klasifikasi dan deskripsi lainnya. Nomor kelas suatu koleksi tidak akan bisa ditentukan sebelum subjek didapat, maka dari itu subjek hasil pengindeksan koleksi merupakan kunci awal temu balik informasi. Hasil dari pengindeksan selain katalog yakni indeks, bibliografi dan abstrak yang juga berperan sebagai alat bantu telusur dalam temu balik informasi di perpustakaan.

\section{PEMBAHASAN}

\section{Pengindeksan Koleksi}

Menurut Clevelend yang dikutip oleh Nurjannah (2018:13-14), “Indexing is the process identifying information in a knowledge record (text or nontext) an organizing the pointers to that information in tp searchable file", yang artinya pengindeksan adalah proses identifikasi informasi dalam sebuah catatan pengetahuan baik teks ataupun non teks dan pengorganisasian nilai-nilai informasi untuk pencarian file. Pengindeksan merupakan semua kegiatan dalam pembentukan indeks atau sarana temu kembali lainya (katalog dan bibliografi) atau semua teknik bibliografi yang mensyaratkan adanya pemahaman mengenai dokumen yang ditangani serta kemempuan dalam menerapkan peraturan pengkatalogan (cataloguing rules), membuat analisis subjek, menggunakan alat bantu untuk menentukan kandungan intelektual atau subjek dokumen serta tidak terbatas pada penyusunan catalog (Raudhoh, 2012).Menurut Siregar dalam Skripsi Skripsi Nurjannah (2018:14), pengindeksan (indexing) terjadi pada tahap masukan sistem informasi dan mancakup proses-proses seperti pencatatan ciri-ciri dokumen yang penting, analisis isi dokumen, klasifikasi dan pembuatan entri katalog. Sedangkan koleksi dalam UU No.43 tahun 2007 tentang perpustakaan, adalah semua informasi dalam bentuk karya tulis, karya cetak, dan/atau karya rekam dalam berbagai media yang mempunyai nilai pendidikan, yang dihimpun, diolah, dan dilayankan.

Pengindeksan merupakan sebuah kegiatan penting di perpustakaan dalam proses pengolahan bahan pustaka sebelum siap dilayangkan di ruang pelayanan. Sekurang-kurangnya dalam rentang 1 tahun pengadaan koleksi melalui pembelian, pengindeksan perlu dilakukan pustakawan, belum lagi jika terdapat hibah dari Perpustakaan Nasional, dan unit instansi/lembaga lainnya. Artinya pengindeksan dilakukan setiap bahan pustaka baru datang.Bahan pustaka yang baru datang baik itu diperoleh melalui pembelian, tukar-menukar, maupun hadiah perlu diproses 
terlebih dahulu sebelum disusun di rak. Pengindeksan dimulai dari mencatat informasi-informasi fisik dan isi bahan pustaka yang akan menuntun kepada analisis subjek dan pemberian nomor kelas sehingga koleksi dapat disusun sesuai urutan penyusunan yang sistematis dan mudah ditemukan. Selain itu pengindeksan juga menghasilkan (output) berupa alat bantu telusur seperti katalog, indeks, bibliografi dan lainnya. Singkatnya pengindeksan melahirkan keyword yang berasal dari dokumen yang diolah itu sendiri, keyword inilah representasi atau wakil dari dokumen yang berfungsi vital dalam temu balik informasi koleksi perpustakaan.

Dalam pengindeksan, dikenal bahasa alamiah dan bahasa indeks yang digunakan untuk mengarahkan pemustaka menuju informasi yang dibutuhkan. Bahasa indeks merupakan bahasa yang dipakai sebagai keyword koleksi-koleksi di perpustakaan. Bahasa alamiah juga dipakai namun hanya sebagai penunjang bahasa indeks. Untuk lebih jelas mengenai kedua bahasa penelusuran ini, perhatikan defenisi oleh ahli dibawah ini :

\section{Bahasa Alamiah}

Menurut Mattoon dalam Kusumawardani (2013:6), "The term natural language indicates that such tags typically reflect natural speech, and are usually less formal, without a structured defenition, hierarchy, or external control. Examples of natural language indexing can be seen an social media websites, such as facebook, as well as image-sharing domains, such as flickr", yang artinya bahasa alami menunjukan bahwa tag tersebut mencerminkan ucapan yang alami, dan biasanya kurang formal, tanpa defenisi yang terstruktur, hierarki, atau kontrol eksternal. Contoh pengindeksan bahasa alami dapat dilihat pada situs media sosial seperti facebook, serta gambar sharing seperti flickr.

Bahasa indeks

Bahasa indeks juga dapat disebut sebagai controlled vocabulary atau bahasa terkontrol. Jika dilihat dari pengertiannya, Sulistyo-Basuki yang dikutip Kusumawardani (2018:7), mengatakan bahwa bahasa terkontrol merupakan bahasa buatan yang khusus dibuat serta dirancang untuk menggunakan isi subyek dokumen dan permintaan informasi, agar dapat mengetahui lokasi kumpulan informasi dokumen yang menjawab pertanyaan tertentu disebut sebagai bahasa pengindeksan.

Bahasa indeks dan bahasa alamiah umumnya ditemukan didalam daftar tajuk subjek dan Thesaurus, lengkapnya sebagai berikut :

1). Daftar Tajuk Subjek

Menurut Suwarno (2016:115), daftar tajuk subjek adalah suatu daftar standar yang dipakai oleh para pustakawan dan dokumentalis sebagai pedoman untuk menetapkan tajuk subjek dari karya-karya yang akan dibuatkan katalog subjek. Sedangkan menurut Tairas dan Soekarman ( 2009: xix), daftar tajuk subjek adalah suatu daftar yang dipakai oleh para pustakawan sebagai pedoman untuk menetapkan tajuk subjek dari buku-buku yang akan dibuatkan entri subjek. Lanjutnya, daftar ini biasanya disusun 
berdasarkan pengalaman bertahun-tahun sehingga tajuk-tajuk subjek yang terdaftar itu dianggap sudah baku atau standar, walaupun sewaktu-waktu dapat diadakan penyempurnaan dan bukan tidak mungkin terjadi modifikasi pada subjek-subjek yang telah ditetapkan semula.Daftar tajuk subjek itu umumnya luas, meliputi seluruh bidang ilmu pengetahuan. Namun ada juga daftar tajuk subjek yang berisi 1 bidang keilmuan seperti bidang pertanian, politik, dan lain sebagainya. Dibawah ini merupakan beberapa acuan yang terdapat didalam daftar tajuk subjek yaitu :

Lihat. Acuan ini digunakan untuk menuntun penelusur dari tajuk yang tak dipakai menuju tajuk yang digunakan. Misalkan: Batminton Lihat Bulutangkis.

Lihat Juga. Acuan ini digunakan untuk menunjukan tajuk subjek lain yang mempunyai hubungan dengan tajuk yang dicari. Misalkan:Tsunami Lihat Juga Gempa Bumi.

Thesaurus

Dalam Kamus Lengkap Bahasa Indonesia, kata thesaurus mempunyai arti sebagai "buku referensi berupa daftar kata dengan sinonimnya". Dalam Webster's New Twentieth Century DictionarydalamTambunan ( 2012 : 2), menyatakan tesaurus berasal dari bahasa Yunani yang mempunyai arti suatu buku berupa perbendaharaan kata-kata, seperti kamus, ensiklopedi, bukubuku sinonim dan antonim. Menurut Raudhoh Raudhoh (2012), Thesaurus adalah sarana pengawasan istilah yang digunakan untuk penerjemahan dari bahasa alamiah dokumen, pengindeks dan pemakai, ke bahasa yang lebih terkendali.Tesaurus diartikan sebagai alat untuk pengawasan kosakata(vocabulary control). Menurutnya ia berfungsi membantu meningkatkan kualitas penelusuran informasi, yaitu memberikan bimbingan kepada para pengindeks dan penelusur informasi tentang istilah-istilah mana yang harus digunakan (Leide, 2002:1). Biasanya tesaurus dibuat untuk mengindeks dan menelusuri informasi pada subjek area tertentu. Misalnya, tesaurus pendidikan, tesaurus pertanian, tesaurus arsitektur, tesaurus hukum dan lain-lain. Oleh karena itu ruang lingkup dari tesaurus itu khusus bidangbidang ilmu yang dipilih.

Tesaurus biasanya terdiri atas tiga bagian. Bagian utama memperlihatkan kedudukan kata-kata atau istilah dalam suatu struktur dan disebut susunan hierarkis. Bagian berikutnya merupakan daftar istilah-istilah tadi, disusun menurut abjad dan diperlihatkan istilahistilah lain yang berhubungan serta jenis hubungannya, disebut alfabetis. Bagian terakhir adalah indeks yang kebanyakan dalam bentuk permutasi (Tambunan, 2012:3).

Selain bahasa ilmiah, di dalam pengindeksan koleksi terdapat proses pengindeksan koleksi dengan melalui dua tahap yaitu sebagai berikut ini:

\section{Pengkatalogan Deskriptif}

Pengkatalogan deskriptif merupakan kegiatan pencatatan dokumen yang akan menghasilkan wakil dokumen atau cantuman bibliografi yang terdiri dari 8 daerah pokok, yaitu : 
1) dan Kepengarangan: berisi judul utama dan anak judul serta keterangan kepengarangan

2) berisi pernyataan edisi koleksi

3) Khusus

4)

$\mathrm{m}$ : impresum berisi tempat, penerbit dan tahun koleksi diterbitkan

5) berisi mengenai jumblah halaman koleksi;pernyataan ilustrasi jika ada dan keterangan lebar dan panjang koleksi (buku).

6)

7)

: berisi catatan tambahan mengenai isi buku terkait bibliografi, indeks, judul asli dan lain-lain.

8)

International Standard Book Number ialah standar nasional nomor dari koleksi.

a.

eksan Subjek

Pengind

Dalam tahap pengindeksan subjek dibagi menjadi dua tahap, yaitu sebagai berikut :

1)

Subjek

Dalam analisis subjek, indexer (pengindeks) akan mempelajari isi dokumen untuk mengetahui subjek-subjek apa saja terkait dengannya. Dalam hal ini, biasanya indexer akan melihat judul dokumen, daftar isi, pendahuluan, sebab pada bagian tersebutlah biasanya informasi mengenai subjek apa yang fokus dibahas ditemukan.Dalam sebuah bahan pustaka pasti terdapat pokok permasalahan atau pembahasan, pembahasan tersebut bisa tentang satu subjek atau beberapa subjek(Sudiar dkk, 2016:58).

2)

mahan

Penerje

Kegiatan penerjemahan merupakan kelanjutan dari tahap sebelumnya yaitu analisis subjek. Tahap ini sudah mencocokan hasil analisis dengan bagan klasifikasi dan daftar tajuk subjek, hasilnya akan siap dipakai.

\section{Temu Balik Informasi}

Kata informasi dalam Kamus Lengkap Bahasa Indonesia berarti penerangan, keterangan; pemberitahuan; kabar atau berita tentang sesuatu; keseluruhan makna yang menunjang amanat yang terlihat di dalam bagianbagian amanat itu(Boediono:137). Menurut Kusumawardani (2013:4), temu balik informasi merupakan proses dimana penguna dapat menemukan informasi yang 
Jati Rahadi, Fridinanti Yusufhin; Pentingnya Pengindeksan Koleksi Dalam Proses Temu Balik Informasi Di Perpustakaan

dibutuhkan pada penyedia informasi dengan dibantu oleh sistem yang sudah disediakan.

Informasi merupakan sebuah aset yang sangat berharga, di dunia ini terdapat banyak informasi yang melimpahruah. Informasi dapat diperoleh oleh siapapun, dimanapun, dan kapanpun karena informasi terlahir sepanjang waktu. Oleh karena itulah tinggal bagaimana seseorang mendapatkannya, memanfaatkanya dan mengemas ulang informasi tersebut sehingga dapat dimanfaatkan oleh masyarakat luas.

Istilah temu balik informasi lahir dari perkembangan informasi itu sendiri, dimulai dari mendapatkan informasi, kemudian mengelolahnya,memanfaatkanya, menyimpannya, dan bagaimana informasi tersebut dapat kembali ditemukan. Dalam perkembangannya, di zaman yang segala hal telah terkomputerisasi, temu kembali informasi dikenal dengan istilah IR (Information Retrieval).Menurut Suwarno (2016:249), dalam buku Organisasi Informasi Perpustakaan, memberikan dalam sebuah defenisi sebagai berikut :

Information Retrieval (IR) is finding materiil (usually documents) of an unstructured nature (usually text) that satisfies an information need from within large collections (usually stored on computers).

Yang artinya bahwa Information Retrieval(IR) adalah proses menemukan bahan (biasanya dokumen) dari bersifat terstructur (biasanya teks) yang memenuhi kebutuhan informasi dari dalam koleksi besar (biasanya disimpan di komputer).Selanjutnya, Pendit dkk (2007:95)menyatakan bahwa Information Retrieval merujuk kepada keseluruhan kegiatan yang meliputi pembuatan wakil informasi (representation), penyimpanan (storage), pengaturan (organization) sampai ke pengambilan (access).

\section{Pentingnya Pengindeksan dalam Temu Balik Informasi di Perpustakaan}

Hasil pengindeksan koleksi/dokumen menghasilkan dua bentuk yaitu jajaran koleksi di rak dan alat bantu telusur. Keduanya mempunyai andil penting dalam proses temu kembali informasi di perpustakaan. Oleh karena itu, diperlukan kecermatan dalam proses pengindeksan agar tidak salah mengindeks. Kesalahan yang berakibat fatal jika terjadi biasanya yaitu :

Kesalahan-kesalahan diatas jika terjadi akan mengakibatkan kesalahan penelusuran informasi, sehingga temu balik informasi tidak berjalan dengan cepat dan akurat.Kesalahan dalam penginputan nama penulis dan judul koleksi berakibat keliru pada proses pembuatan katalog pengarang dan 
Jati Rahadi, Fridinanti Yusufhin; Pentingnya Pengindeksan Koleksi Dalam Proses Temu Balik Informasi Di Perpustakaan

katalog judul. Kesalahan pembuatan kedua jenis katalog tersebut membuat penelusur menjadi binggung dalam penelusuran koleksi di katalog manual maupun di katalog online (OPAC). Bukan hanya itu, kesalahan pada katalog judul juga memberi dampak kepada proses pengindeksan subjek. Analisis subjek dan penerjemahan hasil analisis akan rancu karena judul merupakan aspek yang paling diperhatikan dari awal oleh indexer/pustakawan untuk menentukan subjek dari sebuah koleksi. Dan yang paing terlihat dari kekeliruan pengindeksan adalah pemberian nomor klasifikasi.

Menurut Basuki (1991:395) dalam buku Pengantar Ilmu Perpustakaan, klasifikasi adalah susunan sistematik terhadap buku dan bahan pustaka lain atau katalog atau entri indeks berdasarkan subjek, dalam cara paling berguna bagi mereka yang membaca atau mencari informasi.Sederhananya, kesalahan pengindeksan berakibat keliru dalam memberi subjek koleksi dan nomor kelas sehingga penjajaran koleksi di rak akan salah. Alat telusur yang dihasilkan juga akan sama kelirunya. Dengan begitu, proses temu kembali informasi akan bermasalah, akibatnya pemustaka akan binggung dan tersesat dalam mencari literatur-literatur yang dibutuhkan.

\section{KESIMPULAN}

Pada hakikatnya, pengindeksan koleksi sangat vital dalam temu balik informasi di perpustakaan. Pengindeksan melahirkan keyword yang berasal dari dokumen tersebut yang telah diolah. Dari keywordtersebutadanya representasi atau wakil dari dokumen yang berfungsi vital dalam temu balik informasi koleksi perpustakaan.Kesalahan-kesalahan yang terjadi dalam proses pengindeksan koleksi akan berakibat fatal jika berkaitan dengan nama penulis/penggarang, judul koleksi, analisis subjek dan sebagainya. Karena kesalahan kecil, akan mempengaruhi proses selanjutnya pada tahapan pengindeksan, dan tahapan kegiatan ini sangat berpengaruh dalam temu kembali informasi. Maka dari itu, proses pengindeksan sangat diperlukan dalam penelusuran informasi. Selain itu, skill dan kecermatan oleh pustakawan, indexer, dan subjek spesialis sangat diperlakukan dalam proses pengindeksan agar tidak ada kesalahan dalam temu balik informasi. Dalam proses ini akan berjalan dengan optimal, cepat, dan akurat serta mudah. Sehingga tujuan yang diharapkan olehperpustakaan tercapai.

\section{Daftar Pustaka}

Basuki, Sulistyo. (1991). Pengantar Ilmu Perpustakaan. Jakarta : Gramedia Pustaka Utama. . (2004). Pengantar Dokumentasi. Bandung: Rekayasa Sains.

Boediono. Kamus Lengkap Bahasa Indonesia. Jakarta : Bintang Indonesia.

Kusumawardani, Devita. (2013). Temu Kembali Informasi dengan Keyword ( Studi Deskriptif tentang Sistem Teтu Kembali Informasi dengan Controlled Vocabulary pada Field Judul, Subjek, dan Pengarang di Perpustakaan Universitas Airlangga). Jurnal Unair Vol.2 No.1 (2013).

Leide, John E. (2002). Pedoman Penyusunan Tesaurus. Jakarta : Ditperta Depag RI, Cida, McGill-Project 
Jati Rahadi, Fridinanti Yusufhin; Pentingnya Pengindeksan Koleksi Dalam Proses Temu Balik Informasi Di Perpustakaan

Nurjannah, Junia Eva. (2018). "Skripsi”. Pengindeksan Subjek Pada Perpustakaan Universitas Sumatera Utara. Repository Universitas Sumatera Utara.

Pendit, Putu Laxtman dkk. (2007). Perpustakaan Digital : perspektif perpustakaan perguruan tinggi indonesia. Jakarta: Sagung Seto

Rudianto. (2017). Aplikasi Teknologi Informasi Berbasis SLiMS Di Perpustakaan Uin Sulthan Thaha Saifuddin Jambi. Jurnal Baitul Ulum FAH UIN Jambi Vol.1 No.1 (2017).

Sudiar, Nining, dkk. (2016). Penyengaran Pola Pengindeksan Subjek. Jurnal Pustaka Budaya Vol.3 No.1 (2016).

Suhendar, Yaya. (2010). Pedoman Katalogisasi : cara mudah membuat katalog perpustakaan. Jakarta : Kencana

Suwarno, Wiji. (2016).Organisasi Informasi Perpustakaan : Pendekatan Teori dan Praktik. Jakarta : Rajawali Pers

Tairas, J.N.B. dan Soekarman K. (2009). Daftar Tajuk Subjek untuk Perpustakaan : edisi ringkas. Jakarta : Gunung Mulia

Tambunan, Komariah. (2012). Tesaurus Bioteknologi : Sebagai Alat Bantu Pengindeksan Dokumen. Jurnal Dokumentasi dan Informasi Vol.33 No.2 (2012)

Undang-Undang No. 43 Tahun 2007 Tentang Perpustakaan. Jakarta: Perpustakaan Nasional RI

Zakia, Raudhoh. (2012). "Materi Bahan Ajar Mata Kuliah Kosakata Indeks. Prodi Ilmu Perpustakaan UIN STS Jambi” : Kosakata Indeks. Prodi Ilmu Perpustakaan UIN STS Jambi

. (2012). "Materi Bahan Ajar Mata Kuliah Kosakata Indeks. Prodi Ilmu Perpustakaan UIN STS Jambi”: Defenisi dan Komponen Tesaurus. Prodi Ilmu Perpustakaan UIN STS Jambi 